\title{
Desain Peralatan Memasak untuk Penderita Artritis dan Carpal Tunnel Syndrome
}

\author{
Salsa Sabhila dan Agus Windharto. \\ Jurusan Desain Produk Industri, Fakultas Tenik Sipil dan Perencanaan, Institut Teknologi Sepuluh Nopember (ITS) \\ Jl. Arief Rahman Hakim, Surabaya 60111 Indonesia \\ e-mail: itsdesigncenter@yahoo.com
}

\begin{abstract}
Abstrak - Arthritis merupakan penyakit yang disebabkan peradangan pada persendian tulang, sedangkan Carpal Tunnel Syndrome atau lebih dikenal sebagai CTS adalah penyempitan terowongan karpal pada tangan manusia yang di dalamnya terdapat syaraf, akibat penyempitan ini membuat syaraf terjepit dan berkurangnya kemampuan bergerak pada stuktur tangan manusia. CTS bias jadi menjadi komplikasi dari arthritis yang telah diderita cukup lama. Berdasarkan hasil Riset Kesehatan Dasar tahun 2013 oleh Kementrian Kesehatan Republik Indonesia, artrtitis menjadi salah satu penyakit yang paling banyak menyerang masyarakat di Indonesia khususnya lansia yaitu sebesar 51,9\%. Akibat terjadinya peningkatan jumlah masyarakat penderita arthritis dan CTS menyebabkan menurunnya produktivitas penderita tersebut dalam bekerja dan beraktivitas, salah satunya ialah dalam memasak [1]. Di Indonesia dengan keberagaman masakan yang berbeda dengan cara western membuat penderita arthritis di Indonesia tidak dapat menggunakan alat bantu masak yang dijual bebas di internet. Tujuan utama dari perancangan ini adalah mendesain peralatan memasak untuk penderita arthritis dan CTS. Proses desain dimulai dengan mengumpulkan data dan mengidentifikasi masalah menggunakan metode interview, shadowing, story telling, usability test dan affinity diagram. Hasil data tersebut diolah untuk memberikan desain yang ringan dan nyaman atau lebih dikenal dengan sebutan Arthritis Friendly. Produk terwujud dalam satu set perlengkapan memasak yang terdiri dari ulekan, cobek, sudip, spatula, sendok sayur, centong dan pengocok telur dan pisau yang telah disesuaikan dengan kebutuhan penderita arthritis dan CTS.
\end{abstract}

Kata Kunci- Artritis, CTS, Alat Memasak, Kemampuan Beraktivitas, Arthritis Friendly.

\section{PENDAHULUAN}

A RTHRITIS atau disebut juga radang sendi merupakan penyakit yang disebabkan peradangan pada persendian tulang. Artritis dapat diidentifikasi dengan ciri-ciri rasa nyeri dan perubahan fisik pada sendi. Pada umumnya arthritis digolongkan menjadi 3 jenis yang paling utama, antara lain rheumathoid arthritis(RA), gout arthritis(gout), dan osteoarthritis $(O A)$. Baik RA, gout dan OA memiliki efek yang sama yaitu nyeri pada sendi namun yang membedakan ialah penyebabnya.

Menurut Arthritis Foundation(2016), pria usia kerja dan perempuan (usia 18-64) dengan arthritis kurang mungkin untuk dipekerjakan daripada usia yang sama tanpa arthritis. Sepertiga orang usia kerja dengan arthritis memiliki keterbatasan dalam kemampuan mereka untuk bekerja, jenis pekerjaan yang bisa mereka lakukan atau apakah mereka dapat bekerja paruh waktu atau penuh waktu. Dan orang dewasa dengan artritis atau CTS lebih sering tidak hadir atau tidak dapat bekerja setiap tahun karena sakit atau cedera daripada orang dewasa dengan kondisi medis lainnya.

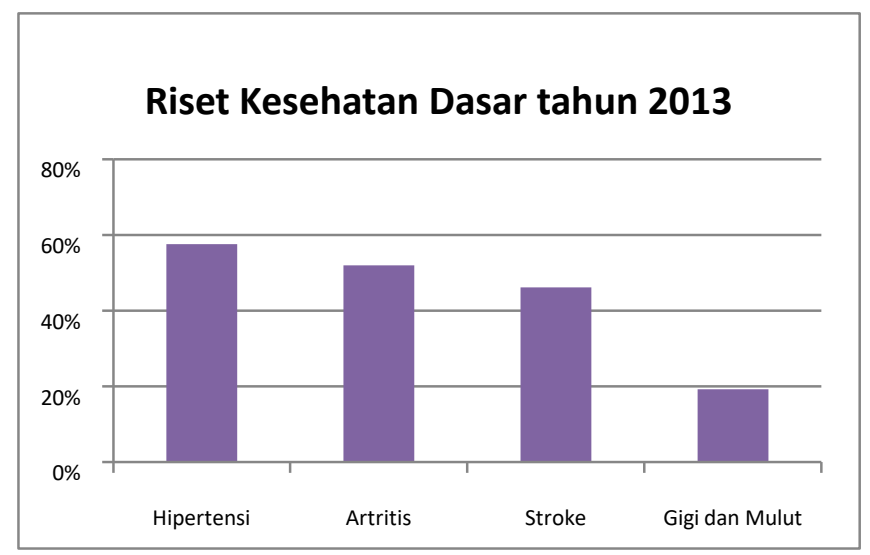

Gambar 1. Hasil Riset Kesehatan Dasar pada tahun 2013.

(www.depkes.go.id)

Berdasarkan hasil Riset Kesehatan Dasar tahun 2013 oleh Kementrian Kesehatan Republik Indonesia, artrtitis menjadi salah satu penyakit yang paling banyak menyerang masyarakat di Indonesia khususnya lansia yaitu sebesar 51,9\% [1]. Itu mengindikasikan bahwa dari sepuluh masyarakat Indonesia, enam orang diantaranya adalah penderita artritis. Dari rentang usia 25-75 tahun pada penderita arthritis dan CTS, presentase terbanyak $68,6 \%$ adalah wanita yang aktif menjadi Ibu Rumah Tangga yang lebih banyak menghabiskan waktu di dapur. Dengan latar belakang usia diatas, aktivitas yang paling sering dilakukan ialah aktivitas di dapur yang menggunakan peralatan dapur dan melibatkan tangan dan bahu untuk aktif bergerak [2].

\section{Kesulitan dalam kegiatan masak memasak.}

Akibat kemampuan genggam dan pergerakan pergelangan tangan serta jari yang banyak berkurang, membuat kegiatan memasak dan menghaluskan bumbu menjadi kegiatan yang menyakitkan. Setelah ditinjau lebih dalam, hal ini disebabkan oleh salah satunya ialah alat yang digunakan membutuhkan usaha yang cukup besar. 


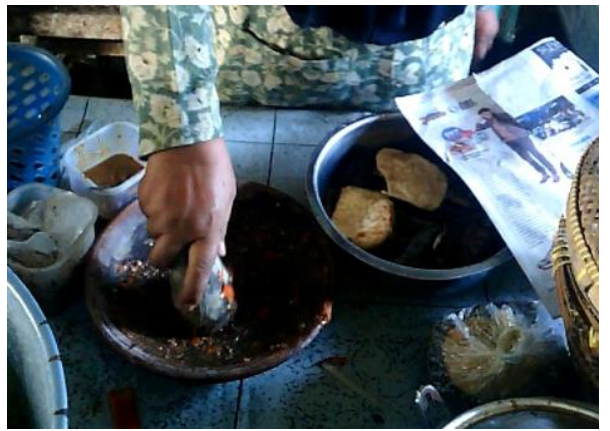

Gambar 2. Mengulek adalah salah satu kegiatan yang berat dilakukan.

Meskipun terjadi peningkatan angka penderita arthritis dan CTS, hingga saat ini belum ada pengembangan produk peralatan rumah tangga yang ramah untuk digunakan oleh penderita arthritis dan CTS di Indonesia. Pengembangan produk ini dianggap penting karena selain dapat mendampingi dan mengimbangi kemampuan kerja penderita yang semakin berkurang, juga dapat memberikan suasana baru pada desain produk appliance Indonesia yang saat ini para produsen peralatan rumah tangga sedang banyak menyerukan alat-alat yang menunjang kesehatan penggunanya.Selain itu, peralatan yang kini digunakan oleh para penderita sering dikeluhkan karena beratnya alat yang digunakan membuat tangan bergetar sehingga tidak mampu lagi untuk menggunakan alat tersebut. Para penderita memaparkan bahwa alat yang paling sering digunakan di dapur ialah ulekan.

Pada titik tertentu, ulekan tidak dapat digunakan selain karena berat juga penggunaannya yang butuh tekanan padahal kemampuan genggam berkurang sehingga membuat hasil ulekan tidak maksimal. Pada akhirnya penderita menggunakan alat lain seperti blender untuk menghaluskan bumbu atau meminta tolong pada orang lain untuk melakukan kegiatan mengulek.Terlebih lagi, pernggunaan alat yang tidak sesuai dengan kemampuan genggam seseorang maka sama saja mempersulit kemungkinan seseorang tersebut untuk dapat segera sembuh dari arthritis dan CTS.

\section{METODE PERANCANGAN}

\section{A. Tahap Pengambilan Data}

Metode yang digunakan dalam mendesain peralatan rumah tangga ialah Deep Interview, Usability Test, Ansys Simulation, dan Affinity Diagramming, dimana yang perlu diperhatikan adalah penggunanya. Dalam hal ini user dengan arthritis dan carpal tunnel syndrome yang langsung berhubungan dengan peralatan rumah tangga yang akan dirancang antara lain adalah: ibu rumah tangga, bapak rumah tangga, ibu hamil.

1. Ibu Rumah Tangga

Ibu Rumah Tangga adalah user utama dalam rancangan peralatan rumah tangga berikut sehingga observasi akan lebih mendalam pada user tipe berikut ini. Usia ibu rumah tangga pada umumnya 30-70 tahun. Data yang diperlukan ialah analisis kegiatan sehari-hari sehingga dapat diketahui kebutuhan yang ingin dipenuhi. Data tersebut dapat terkumpul dengan metode shadowing dan observasi. Selain itu juga dapat dengan metode deep interview mengenai peralatan yang selama ini user pakai selama menderita arthritis dan CTS. Permasalahan akan muncul seiring terkumpulnya data-data kemudian penelitian dapat dilanjutkan menuju pengembangan konsep desain.

\section{Bapak Rumah Tangga}

User berikut ialah user sekunder yang pada umumnya tinggal dirumah namun tidak sepenuhnya menggunakan semua peralatan rumah tangga. Namun tidak menutup kemungkinan bahwa user pria juga memiliki permasalahan yang sama dengan user wanita. Dengan metode deep interview dan shadowing, data terkumpul dan diakumulasikan dalam bentuk data-data numeric dan data analisis kegiatan. Permasalahan yang dialami bisa jadi sama oleh karena itu setiap kemungkinan harus dapat ditangani agar solusi bias tepat sasaran.

\section{Ibu Hamil}

Ibu hamil adalah user utama penderita CTS. Carpal Tunnel Syndrom menyerang pada masa kehamilan yang dimana pada proses kehamilan akan terjadi penumpukan lemak dan peningkatan berat badan. Akibatnya, bagian tubuh seperti jarijari tangan dan kaki bengkak karena penyempitan syaraf. Oleh karena itu perlu ada metode yang fokus pada kegiatan selama kehamilan yaitu dengan deep interview dan diary studies.

\section{B. Tahap Studi dan Analisis}

Dalam perancangan peralatan untuk penderita arthritis dan CTS diperlukan metode desain yang sesuai agar data yang dibutuhkan dapat terkumpul dengan efektif dan efisien. Metode tersebut secara garis besar dituangkan dalam gambar 3

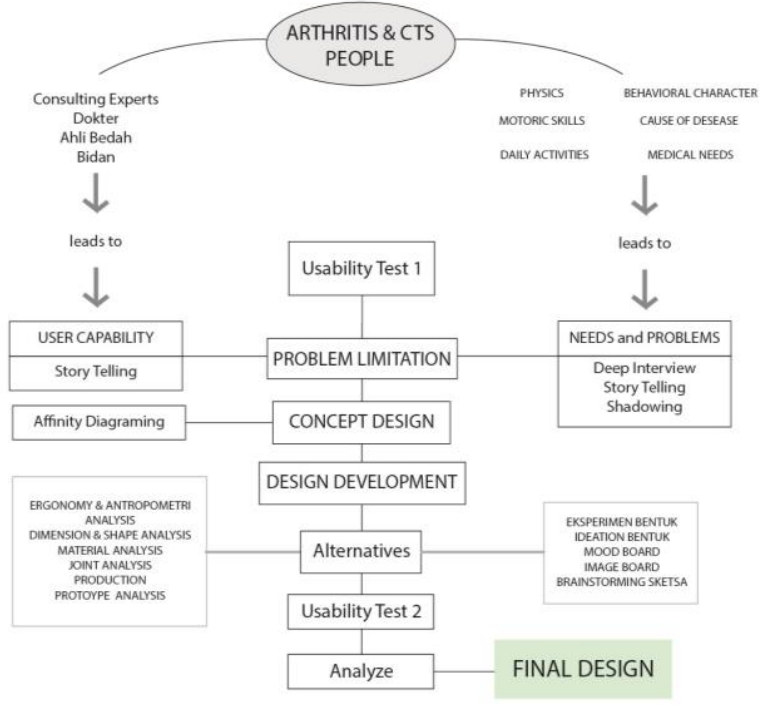

Gambar 3. Skema metode penelitian.

Sebelum melakukan berbagai studi dan analisis, yang pertama kali dilakukan ialah melakukan studi literatur mengenai artritis dan carpal tunnel syndrome dari sisi anatomi tubuh dan kesehatan. Studi tersebut dilakukan untuk mendukung landasan analisis biomekanika pengguna. 


\section{KONSEP PERANCANGAN}

\section{A. Analisis Biomekanika}

Biomekanika merupakan satu bidang ilmu yang berhubungan mengenai pergerakan tubuh manusia yang erat kaitannya dengan otot, tulang, ligament dan sendi manusia ditunjang dengan ilmu mekanika, antropometri, biologi dan fisika [3]. Ilmu biomekanika ini menjadi salah satu dasaran dalam mendesain peralatan memasak untuk penderita arthritis dan carpal tunnel syndrome.

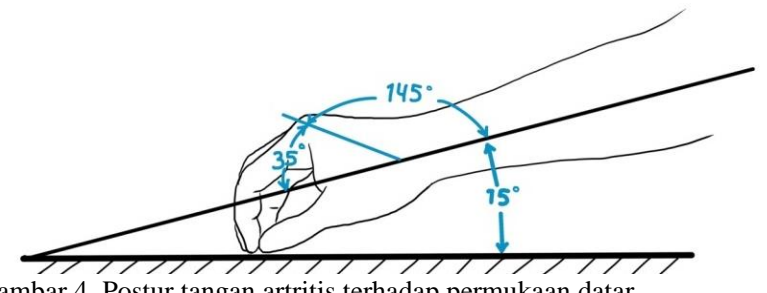

Gambar 4. Postur tangan artritis terhadap permukaan datar.

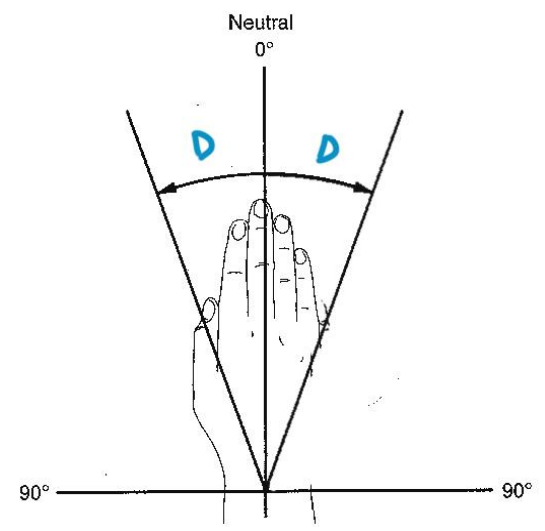

Gambar 5. Ulnar-radial tangan artritis.

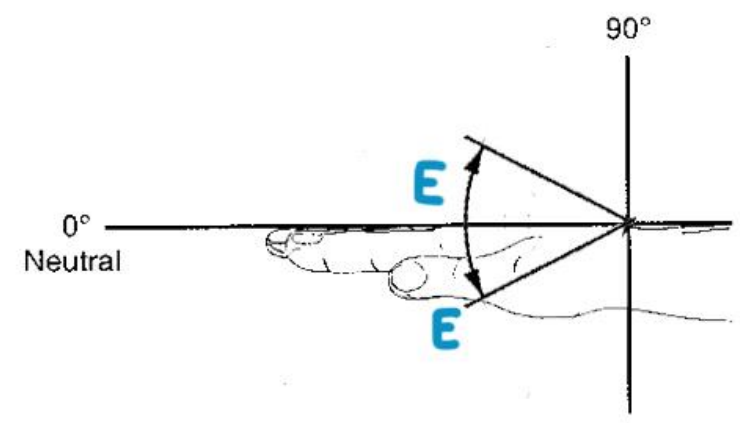

Gambar 6. Flexion-extension.

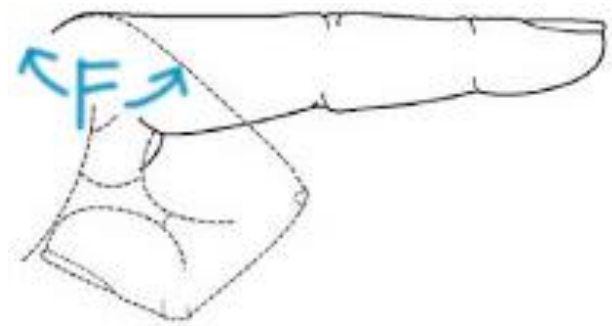

Gambar 7. Sudut deviasi buku jari artritis.
Tabel 1. Biomekanika dasar tangan pengguna

\begin{tabular}{clc}
\hline Notasi & Keterangan & Ukuran \\
\hline A & Sudut antara ibu jari dan metacarpal & $35 \circ$ \\
B & Sudut antara ibu jari dan lengan & $145 \circ$ \\
C & Sudut normal jarak antara tangan & $15 \circ$ \\
D & dengan permukaan datar & \\
E & Elnar - Radial & $20 \circ$ \\
F & Slexion - Extension & $35 \circ$ \\
& Beban deviasi buku jari & $85 \circ$ \\
& Kekuatan genggam tangan kanan & $2 \mathrm{~kg}$ \\
& $6.87 \mathrm{psi}$ \\
\hline
\end{tabular}
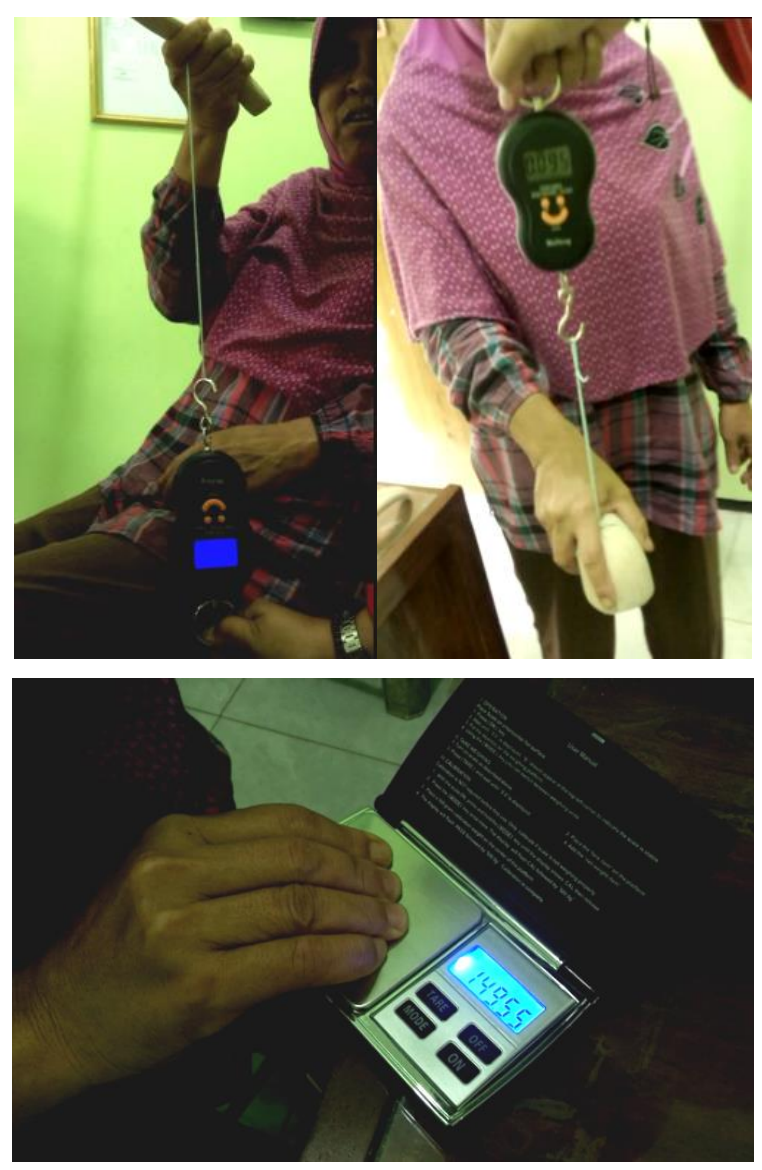

Gambar 8. Percobaan pada 3 Desember 2016 dengan responden Ibu Nanik

Pengukuran menggunakan alat dibutuhkan untuk mengetahui seberapa besar gaya dan massa yang diberikan oleh user maupun batas besarnya massa yang dapat ditoleransi oleh user. Berikut ialah hasil pengukuran menggunakan alat timbangan emas dan timbangan digital yang dilakukan pada tanggal 3 Desember 2016 pukul 12.41 di Puskesmas Trosobo. Responden pada percobaan ialah Ibu Nanik, usia 55 tahun asal Sidoarjo.

Percobaan dibawah ini dilakukan dengan mencoba empat produk yaitu sendok sayur, spatula, sendok nasi dan ulekan. Responden diminta untuk menggunakan produk-produk 
tersebut yang telah dikaitkan dengan seutas tali dengan panjang $20 \mathrm{~cm} \mathrm{[4].} \mathrm{Produk-produk} \mathrm{tersebut} \mathrm{digunakan} \mathrm{dengan}$ perlakuan posisi tubuh, sudut pergelangan tangan dan pergerakan yang berbeda-beda. Berikut ialah hasil dari percobaan tersebut.

Tabel 2. Hasil percobaan uji angkat dan genggam pada posisi duduk.

\begin{tabular}{|c|c|c|c|c|c|c|c|}
\hline \multirow{3}{*}{ Duduk } & \multicolumn{6}{|c|}{ Hand Motion } & \multirow{3}{*}{$\begin{array}{c}\text { Grip } \\
\text { Strength }\end{array}$} \\
\hline & \multicolumn{2}{|c|}{ Flexion } & \multicolumn{2}{|c|}{ Extension } & \multirow{2}{*}{$\begin{array}{l}\text { Ulnar } \\
60^{\circ}\end{array}$} & \multirow{2}{*}{$\frac{\text { Radial }}{60^{\circ}}$} & \\
\hline & $30^{\circ}$ & $60^{\circ}$ & $30^{\circ}$ & $60^{\circ}$ & & & \\
\hline Spatula & 1.8 & 2.3 & 2.2 & 1.9 & 1.9 & $1.9 \mathrm{~kg}$ & \\
\hline Ulekan & - & $\begin{array}{l}4.3 \\
\mathrm{~kg}\end{array}$ & - & - & - & - & $149.55-$ \\
\hline $\begin{array}{c}\text { Sendok } \\
\text { Nasi }\end{array}$ & $\begin{array}{l}4.4 \\
\mathrm{~kg}\end{array}$ & $\begin{array}{l}3.8 \\
\mathrm{~kg}\end{array}$ & $\begin{array}{l}3.1 \\
\mathrm{~kg}\end{array}$ & $\begin{array}{l}2.2 \\
\mathrm{~kg}\end{array}$ & $\begin{array}{l}4.6 \\
\mathrm{~kg}\end{array}$ & $3.8 \mathrm{~kg}$ & gr \\
\hline $\begin{array}{c}\text { Sendok } \\
\text { Sayur }\end{array}$ & $\begin{array}{l}3.4 \\
\mathrm{~kg}\end{array}$ & $\begin{array}{l}3.0 \\
\mathrm{~kg}\end{array}$ & $\begin{array}{l}2.9 \\
\mathrm{~kg}\end{array}$ & $\begin{array}{l}3.4 \\
\mathrm{~kg}\end{array}$ & $\begin{array}{l}4.7 \\
\mathrm{~kg}\end{array}$ & $3.5 \mathrm{~kg}$ & \\
\hline
\end{tabular}

Tabel 3. Hasil percobaan uji angkat dan genggam pada posisi berdiri.

\begin{tabular}{|c|c|c|c|c|c|c|c|}
\hline \multirow{3}{*}{ Berdiri } & \multicolumn{6}{|c|}{ Hand Motion } & \multirow{3}{*}{$\begin{array}{l}\text { Grip } \\
\text { Strength }\end{array}$} \\
\hline & \multicolumn{2}{|c|}{ Flexion } & \multicolumn{2}{|c|}{ Extension } & \multirow{2}{*}{$\frac{\text { Ulnar }}{60^{\circ}}$} & \multirow{2}{*}{$\frac{\text { Radial }}{60^{\circ}}$} & \\
\hline & $30^{\circ}$ & $60^{\circ}$ & $30^{\circ}$ & $60^{\circ}$ & & & \\
\hline Spatula & $\begin{array}{l}5.8 \\
\mathrm{~kg}\end{array}$ & $\begin{array}{l}5.4 \\
\mathrm{~kg}\end{array}$ & $\begin{array}{l}6.0 \\
\mathrm{~kg}\end{array}$ & $\begin{array}{l}7.8 \\
\mathrm{~kg}\end{array}$ & $\begin{array}{l}6.0 \\
\mathrm{~kg}\end{array}$ & $6.9 \mathrm{~kg}$ & \\
\hline Ulekan & - & $\begin{array}{l}6.8 \\
\mathrm{~kg}\end{array}$ & - & - & - & - & $\begin{array}{r}149.55- \\
455.03\end{array}$ \\
\hline $\begin{array}{c}\text { Sendok } \\
\text { Nasi }\end{array}$ & $\begin{array}{l}5.7 \\
\mathrm{~kg}\end{array}$ & $\begin{array}{l}7.3 \\
\mathrm{~kg}\end{array}$ & $\begin{array}{l}5.3 \\
\mathrm{~kg}\end{array}$ & $\begin{array}{l}7.8 \\
\mathrm{~kg}\end{array}$ & $\begin{array}{l}5.3 \\
\mathrm{~kg}\end{array}$ & $5.6 \mathrm{~kg}$ & gr \\
\hline $\begin{array}{c}\text { Sendok } \\
\text { Sayur }\end{array}$ & $\begin{array}{l}4.7 \\
\mathrm{~kg}\end{array}$ & $\begin{array}{l}5.4 \\
\mathrm{~kg}\end{array}$ & $\begin{array}{l}4.3 \\
\mathrm{~kg}\end{array}$ & $\begin{array}{l}3.4 \\
\mathrm{~kg}\end{array}$ & $\begin{array}{l}4.2 \\
\mathrm{~kg}\end{array}$ & $5.5 \mathrm{~kg}$ & \\
\hline
\end{tabular}

Tabel 4. Standar acuan berat dan massa produk.

\begin{tabular}{clcc}
\hline No & Standar Acuan & Min & Max \\
\hline 1 & Berat (N) & 1.465 & 4.459 \\
2 & Massa Produk (gr) & 149.55 & 455.03 \\
\hline
\end{tabular}

Berdasarkan tabel diatas, dapat disimpulkan bahwa posisi berdiri lebih mampu menghasilkan kemampuan gaya yang lebih besar dibandingkan posisi duduk. Kemudian, juga dapat disimpulkan bahwa besar sudut $60^{\circ}$ adalah pergerakan sudut yang aman dan nyaman bagi responden sehingga sebagian besar dari hasil dengan pergerakan sudut $60^{\circ}$ menunjukkan angka yang lebih besar dibandingkan dengan pergerakan sudut sebesar $30^{\circ}$. Sehingga hal ini dapat ditarik kesimpulan bahwa posisi berdiri dengan sudut pergelangan tangan sebesar $60^{\circ}$ ialah postur aktivitas dan posisi pergelangan tangan yang dapat menghindarkan pengguna dari cidera saat memasak dalam keadaan menderita arthritis dan CTS.

Melalui hasil percobaan diatas, data mengenai grip strength atau kemampuan genggam responden diolah untuk menjadi standar acuan yang nantinya akan diaplikasikan pada produk. Dengan adanya acuan tersebut, produk diharapkan dapat mengikutinya dan tidak semakin memperburuk kondisi pengguna yang dimana menimbulkan kecelakaan dalam proses memasak. Berikut adalah batas atau standar acuan tersebut.

Tabel 5. Analisis biomekanika pada setiap produk.

\begin{tabular}{|c|c|c|c|c|c|}
\hline No & Produk & $\begin{array}{l}\text { Massa } \\
\text { (gr) }\end{array}$ & $\begin{array}{l}\text { Volume } \\
\left(\mathrm{cm}^{3}\right)\end{array}$ & $\begin{array}{c}\text { Massa } \\
\text { jenis } \\
(\mathrm{gr} / \\
\left.\mathrm{cm}^{3}\right)\end{array}$ & $\begin{array}{l}\text { Berat } \\
(\mathrm{N})\end{array}$ \\
\hline 1 & $\begin{array}{l}\text { Sendok } \\
\text { Sayur }\end{array}$ & 56.58 & 296.856 & 0.543 & 0.555 \\
\hline 2 & Pisau Kecil & 59.94 & 90.72 & 0.661 & 0.587 \\
\hline 3 & Pisau Besar & 116.55 & 141.57 & 0.823 & 1.412 \\
\hline 4 & $\begin{array}{l}\text { Butter } \\
\text { spreader }\end{array}$ & 77.95 & 214.5 & 0.363 & 2.102 \\
\hline 5 & Sendok Nasi & 65.95 & 185.625 & 0.355 & 0.646 \\
\hline 6 & Spatula & 64.90 & 146.034 & 0.447 & 0.640 \\
\hline 7 & Ulekan & 132.16 & 583.1 & 0.226 & 1.295 \\
\hline 8 & $\begin{array}{l}\text { Pengocokan } \\
\text { Telur }\end{array}$ & 83.21 & 148.48 & 0.560 & 0.815 \\
\hline
\end{tabular}

Gambar 9. Ansys Simulation pada 3D Model Ulekan

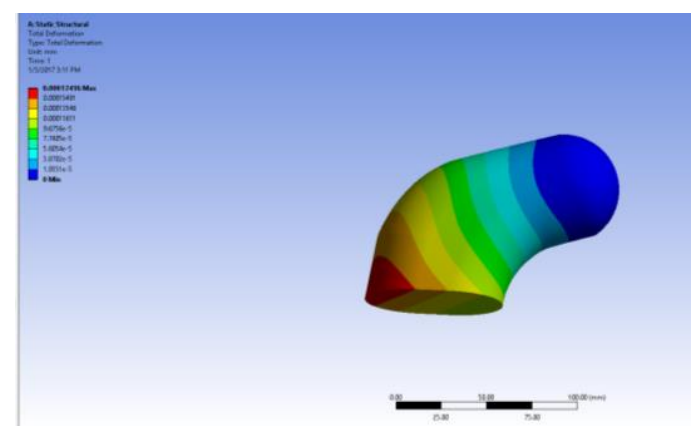

Gambar 10. Ansys Simulation pada 3D Model Ulekan untuk uji tekan. 


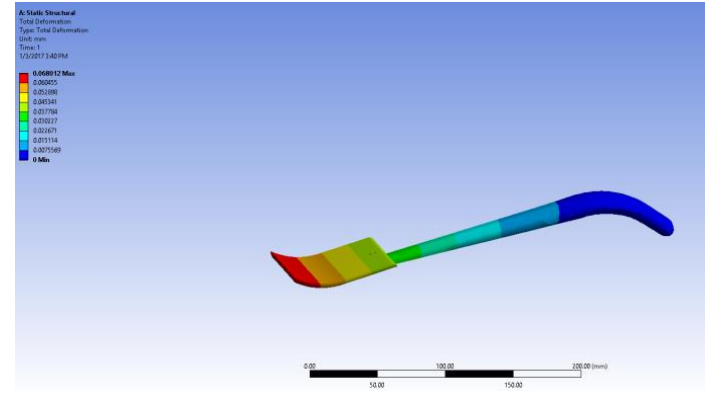

Gambar 11. Ansys Simulation pada 3D Model Spatula.

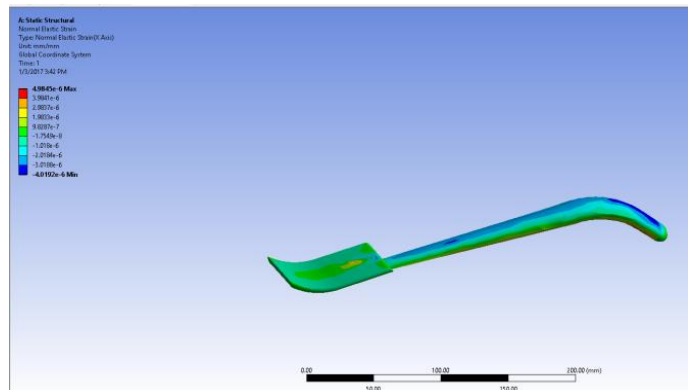

Gambar 12. Ansys Simulation pada 3D Model Spatula untuk uji tekan.

Berdasarkan tabel diatas, maka dapat ditarik kesimpulan bahwa berat atau gaya yang dapat ditolerir oleh pengguna dalam rentang $1.465 \mathrm{~N}$ hingga $4.459 \mathrm{~N}$. Sedangkan massa produk hasil rancangan tidak diijinkan memiliki massa lebih dari rentang antara 149.55 gr - 455.03 gr dengan clearance masing-masing rentang sebesar $200 \mathrm{gr}$.

Dengan adanya acuan pada tabel tersebut maka produk yang telah didesain dapat dievaluasi kesesuaiannya berdasarkan standar tersebut. Setiap produk ditimbang massanya dan diukur volumenya untuk mengetahui massa jenisnya, serta dihitung pula berat gaya yang dihasilkan dari tiap produk.

Berdasarkan tabel diatas, semua produk memiliki massa yang tidak lebih dari 149.55 gr dengan besar berat gaya yang tidak lebih dari $4.459 \mathrm{~N}$. Hal ini membuktikan bahwa semua produk aman untuk digunakan oleh pengguna dan tidak menyebabkan kecelakaan pada saat memasak. Untuk memperkuat data diatas, maka dilakukan simulasi gaya angkat digital. Ditemukan bahwa saat diberikan gaya $4.459 \mathrm{~N}$ alat tidak mengalami tekanan yang besar dan masih berwarna aman di antara biru hingga kuning.

\section{KESIMPULAN DAN RINGKASAN}

1) Pengguna memiliki kemampuan angkat pengguna berkurang sebanyak $20 \%$

2) Pengguna memiliki kemampuan genggam pengguna berkurang sebesar $85 \%$ persen

3) Batas kemampuan daya angkat pengguna ialah $1.465 \mathrm{~N}-$ $4.459 \mathrm{~N}$

4) Batas kemampuan daya genggam pengguna ialah 149.55 $\mathrm{gr}-455.03 \mathrm{gr}$

5) Berat gaya dan massa yang dimiliki oleh tiap produk Tasak tidak lebih dari standar yang telah disebutkan.
6) Produk yang paling mudah digunakan oleh pengguna ialah sendok sayur karena massa yang dimiliki hanya $56.58 \mathrm{gr}$ dengan kebutuhan daya genggam sebesar $0.555 \mathrm{~N}$.

\section{DAFTAR PUSTAKA}

[1] Certification, NSF. (2014). NSF Protocols. Home Product Certification, 2.

[2] Chintyawati, Cicy. Rheumatoid Arthritis. Hubungan Antara Nyeri Rheumatoid Arthritis dengan Tingkat Kemandirian dalam Aktivitas Kehidupan Sehari-Hari Pada Lansia di Posbindu Karang Mekar Wilayah Kerja Puskesmas Pisangan Tangerang Selatan, (2014).15-17.

[3] Kiat Ng, Poh \&Saptari, Adi. (2013). Hand Anthropometry: A Descriptive Analysis on Elderly Malaysians.Adult and Elderly Anthropometry, 193-198.

[4] Nurmianto, Eko. (1996).Ergonomi - Konsep Dasar dan Aplikasinya. Surabaya: Guna Widya. 